\title{
Hassas Kavrama Görevinde Robot Elin Kavrama Kuvvetinin Bulanık Kontrolü için Güvenlik Marjı Veri Tabanının Elde Edilmesi
}

\author{
Canfer İşlek $^{1^{*}}$, Ersin Özdemir ${ }^{2}$ \\ 1* İskenderun Teknik Üniversitesi, Mühendislik ve Doğa Bilimleri Fakültesi, Elektrik-Elektronik Mühendisliği Bölümü, Hatay, Türkiye, (ORCID: 0000-0001-9728- \\ 8431), canferislek.mdbf17@iste.edu.tr \\ 2 İskenderun Teknik Üniversitesi, Mühendislik ve Doğa Bilimleri Fakültesi, Elektrik-Elektronik Mühendisliği Bölümü, Hatay, Türkiye, (ORCID: 0000-0002-6598- \\ 9484), ersin.ozdemir@iste.edu.tr
}

(2nd International Conference on Access to Recent Advances in Engineering and Digitalization (ARACONF)-10-12 March 2021)

(DOI: $10.31590 /$ ejosat.900166)

ATIF/REFERENCE: İşlek, C. \& Özdemir, E. (2021). Hassas Kavrama Görevinde Robot Elin Kavrama Kuvvetinin Bulanık Kontrolü için Güvenlik Marjı Veri Tabanının Elde Edilmesi. European Journal of Science and Technology, (24), 321-327.

\section{$\ddot{O} \mathbf{z}$}

$\mathrm{Bu}$ çalışmanın amacı, bir robot elin kavrama kuvvetinin kontrolünün bulanık mantık denetleyici ile yapılabilmesi için gerekli parametrelerin ayarlanması amacıyla insanların hassas kavrama yeteneğine ait verilerin toplanmasıdır. Literatürde, insanların nesneleri kavrayıp kaldırırken minimum kavrama kuvvetinin üzerine ekledikleri fazladan kuvvet, güvenlik marjı olarak ifade edilmektedir. Bu çalışmada insanlarla farklı ağırlıkta ve farklı yüzey özelliklerinde nesneler için hassas kavrama ve kaldırma deneyleri yapılmıştır. Yapılan deneylerde, insanların hassas kavrama görevinde farklı ağırlıkta ve yüzey özelliklerindeki nesneleri kavrayıp kaldırırken uyguladıkları güvenlik marjı verileri elde edilmiştir. Elde edilen güvenlik marjı verileri, tasarlanacak olan bulanık mantık denetleyicinin veri tabanı olarak değerlendirilecektir. Böylelikle bir robot elin, özellikleri bilinmeyen bir nesneyi hassas bir şekilde kavrayıp kaldırabilmesi sağlanacaktır. Yapılan deneyler sonucunda değişen nesne ağırlığına ve yüzey sürtünme katsayısına bağlı olarak \%9 ile \%20 arasında değişen güvenlik marjı oranları elde edilmiştir. Bu çalışma ile robot elin kavrama kuvveti kontrolü için bulanık mantık tabanlı, değişken güvenlik marjı odaklı bir kavrama kuvveti kontrol yaklaşımı ortaya konulmuştur.

\section{Obtaining the Safety Margin Database for Fuzzy Control of the Grip Force of Robotic Hand in the Precision Grasp Task}

\begin{abstract}
The aim of this study is to collect data on human's precise grip ability in order to adjust the parameters required to control the grip force of a robotic hand with a fuzzy logic controller. In the literature, the extra force that humans add on over of the minimum grip force when grasping and lifting objects is expressed as the safety margin. In this study, precision grip and lifting experiments were carried out for objects of different weights and different surface properties. In the experiments, the safety margin data that people apply while grasping and lifting objects of different weights and different surface properties in precision grasping were obtained. The obtained safety margin data will be evaluated as the database of the fuzzy logic controller to be designed. In this way, it will be ensured that a robotic hand can grip and lift an unknown object precisely. As a result of the experiments, safety margin rates varying between $9 \%$ and $20 \%$ were obtained depending on the varying object weight and coefficient of friction of surface. In this study, a fuzzy logic-based, variable safety margin-oriented grip force control approach is presented for robotic hand grip force control.
\end{abstract}

Keywords: Safety margin, Robotic hand, Grasping force, Precision grasp.

* Sorumlu Yazar: canferislek.mdbf17@iste.edu.tr 


\section{Giriş}

Gelişen teknoloji ile birlikte farklı robot uygulamalarını yaşamımızın her alanında görmekteyiz. Robotlar başta insan olmak üzere canlıların yeteneklerini ve davranışlarını taklit edebilen, elektronik ve mekanik birimlerden oluşan, programlanabilen disiplinler arası cihazlardır. Nesneleri hassas bir şekilde kavrama ve kaldırma yeteneği bir robottan beklenilen en önemli insan yeteneklerinden biridir.

Kavrama, nesnenin yapısal özelliklerine, parmakların durumuna ve kavrama görevinin niteliğine göre güçlü kavrama ve hassas kavrama olarak Cutkosky (1989) tarafindan iki ana sınıfa ayrılmıştır. Bir robot el için kavrama ve manipülasyon, kinematik açıdan hareket planlamasını; statik ve dinamik açıdan ise kuvvet kontrolünü içeren karmaşık bir görevdir (Mavrakis ve ark., 2017). Bu görevin statik ve dinamik açıdan karmaşık olmasının en önemli sebebi kavranan nesne ile ilgili bilinmeyen özelliklerdir. İnsanlar kavrayıp kaldıracakları nesnenin yüzey sürtünme özellikleri, ağırlığ kavrama kuvvetinin niceliğini belirleyecek kesin bir bilgiye sahip değillerdir. $\mathrm{Bu}$ nedenle kavranacak nesne, bir insan ve robot için özellikleri bilinmeyen nesne (Unknown object) (Okamura ve ark., 2000; Bicchi ve ark., 1993; Su ve ark., 2015; Pettersson-Gull ve Johansson, 2018) olmaktadır. Robot elin kavrama kuvveti kontrolü üzerine yapılan birçok çalışmadaki yaklaşım ve metot, Coulomb sürtünme modelini temel almıştır (Bicchi ve ark., 1993; Koda ve Maeno, 2006; Wettels ve ark., 2009; Ho and Hirai, 2011; Morita ve ark., 2018). Bu çalışmaların birçoğunda Coulomb sürtünme denklemi ile hesaplanabilen kayma noktasına odaklanılmıştır. İnsanın ya da robot elin parmakları arasında nesnenin düşmeden asılı durmasını sağlayan temel unsur statik sürtünme kuvvetidir. Bu durum Coulomb sürtünme yasası ile açıklanabilir. Nesneye uygulanacak kavrama kuvvetinin minimum sınır değeri Coulomb sürtünme yasası ile teorik olarak hesaplanabilir. Nesneyi kalıcı deformasyona uğratmayacak minimum kavrama kuvveti ise Hook yasası ile teorik olarak hesaplanabilir. Fakat pratikte nesnelerin yüzeyleri homojen değildir. Kavranıp kaldırılacak nesnenin ağırlığı, yüzey sürtünme özellikleri ve mukavemet değerleri bilinmeyen özelliklerdir. Kombine kuvvet etkileri altında, özellikleri bilinmeyen, kalıcı deformasyona yatkın bir nesnenin bir robot el tarafından kavranıp kaldırılması belirsizlikler içeren karmaşık bir problem ortaya koymaktadır. Bir robot elin hassas kavrama görevi için optimum kavrama kuvvetinin hesaplanabileceği bir matematik model ortaya koymak oldukça zordur.

Literatürde robot el ve bununla ilgili kavrama ve kuvvet kontrolü alanlarında öncü çalışmalar 1980'li yılların başlarından itibaren başlamıştır (Okamura ve ark., 2000). Robot el kavramasına yönelik yapılan çalışmalara insan elinin kavrama becerilerine yönelik yapılan deneysel tıbbi çalışmalar yön vermiştir. (Cutkosky ve Howe, 1990). Bu kapsamında G. Westling ve R. S. Johansson tarafından yön verici çalışmalar ortaya konulmuştur. Birçok çalışmada insanların nesneleri kavrayıp kaldırırken, kavrama kuvvetinin Coulomb sürtünme yasası ile hesaplanabilen minimum sınır değerinin üzerine fazladan kuvvet uyguladıkları ortaya konulmuştur (Westling ve Johansson, 1984; Edin ve ark., 1992; Fu ve Santello, 2018; Kossowsky ve ark., 2020; Gaut, 2020). Bu fazlalık kuvvet genellikle "Güvenlik marjı" olarak ifade edilmiştir. Güvenlik marjının, kavrama kuvvetinin minimum sınır değerine göre yüzde oranı ise "Güvenlik marjı oranı" olarak ifade edilmektedir.
Önceki bazı çalışmalarda güvenlik marjının bir aralıkta değişken olduğu görüşü kabul edilse de güvenlik marjın sabit bir oran ya da katsayı olarak kabul edilmiştir (Hadjiosif and Smith, 2015). Tremblay ve Cutkosky (1993), güvenlik marjı oranının \%15 ila $\% 100$ arasında değiştiğini belirterek, çalışmalarında güvenlik marjı oranını \%20 kabul etmişlerdir. Wettels ve ark. (2009), tahmin edilen kayma noktasının üzerine $\% 20$ güvenlik marj1 oranı uygulamışlardır. Bergmann Tiest ve Kappers (2019), sabit nesne ağırlığı ve yüksek statik sürtünme katsayıları için yaptıkları çalışmalarında güvenlik marjı faktörünü 1,6 (\%60) olarak bildirmişlerdir. Bazı çalışmalarda güvenlik marjının ortalama $\% 10$ ile $\% 40$ arasında değiştiği belirtilmiştir (Johansson ve Flanagan, 2008; Wiertlewski ve ark., 2013; Su ve ark., 2015). Bazı çalışmalarda ise önceki yaygın görüşün aksine güvenlik marjının değişken nesne koşullarından ve çevre koşullarından etkilendiği; sabit bir parametre olmadığı ortaya konulmuştur (Kossowsky ve ark., 2020; Hadjiosif ve Smith, 2015; Gibo ve ark., 2013; Farajian ve ark., 2020; Grover, 2018). Bazı çalışmalarda kavrama kuvvetinin, güvenlik marjı ile ileri besleme şeklinde ayarlanabileceği belirtilmiştir (Hadjiosif ve Smith 2015; Gibo ve ark., 2013). Wang ve ark. (2017) güvenlik marjının tespitine dayalı bir kavrama kuvveti kontrolünün etkinliğini ortaya koymuşlardır.

Güvenlik marjı odaklı yapılan çalışmalarda değişen nesne koşullarına göre ayarlanan bir güvenlik marjı yaklaşımı kabul görmektedir. Bir robot elin hassas kavrama görevi için güvenlik marjının tespiti ile etkin bir kuvvet kontrolü sağlanabileceği belirtilmiştir. Fakat güvenlik marjının değişen nesne özelliklerine bağlı olarak nasıl değiştiği ile ilgili etkin bir matematik model mevcut değildir. Nesneye ve çevresel koşullara bağlı değişkenlikler ve belirsizliklerden dolayı bir matematik model ortaya koyma oldukça güçtür. $\mathrm{Bu}$ nedenle bu çalışmada esnek hesaplama yöntemlerinden bulanık mantık yöntemine dayalı kavrama kuvveti kontrolüne odaklanılmıştır. Bulanık mantık, belirsizliğin fazla olduğu, karmaşık ve matematik modelinin çıkarılması zor olan uygulamalarda başarı ile kullanılmaktadır (Rodriguez ve ark., 2012; Kocabaş, 2017; Tüysüz, 2018). Bulanık mantık insanın yaklaşık akıl yürütme, karar verme özelliklerini ve uzman bilgisini işlenebilir mantıksal algoritmalarla modelleyebilen bir yöntemdir (Zadeh, 1965). İnsanlar, kalıcı deformasyona yatkın, özelliklerini bilmediği nesneleri optimum güvenlik marjı ile hassas bir şekilde kavrayıp kaldırabilme yeteneğine sahiptir (Westling ve Johansson, 1984). $\mathrm{Bu}$ yetenek bebeklikten beri deneyimsel olarak edinilen bir yetenektir.

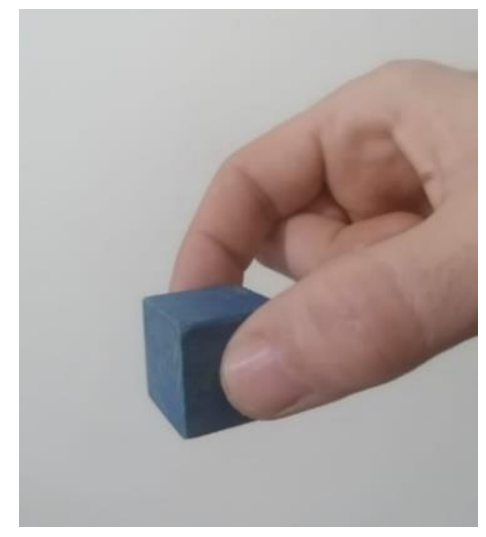

Şekil 1. Ikki Parmaklı Hassas Kavrama

$\mathrm{Bu}$ çalışmanın amacı bir robot elin hassas kavrama görevinde kavrama kuvvetinin bulanık mantık tabanlı kontrolü 
için insanların hassas kavrama becerilerinden güvenlik marjı veri tabanı elde etmektir. Elde edilen güvenlik marjı verileri bulanık mantık denetleyici için veri tabanı olarak kullanılabilecektir. Bu çalışmada insanların hassas kavrama becerilerinden güvenlik marjı verileri elde etmek için bir deney düzeneği hazırlanmıştır. Yapılan deneylerde Şekil 1'de görüldüğü gibi yumuşak parmak uçlu, baş ve işaret parmağın kullanıldığı iki parmaklı hassas kavrama modeli kullanılmıştır.

\section{Materyal ve Metot}

Bu çalışmada yaşları 19 ile 46 arasında, sağ ellerini kullanan 6'sı kadın ve 8'i erkek olmak üzere sağlıklı 14 katılımcı ile 4 farklı nesne yüzey özelliği ve 5 farklı nesne ağırlığı için işaret ve başparmakların kullanıldığı hassas kavrama ve kaldırma deneyleri yapılmıştır. Katılımcılar, bilgilendirilmiş onam formu ile onay vermişlerdir. Tüm deney protokolleri Mustafa Kemal Üniversitesi Girişimsel Olmayan Klinik Araştırmalar Etik Kurulu tarafından onaylanmıştır. Deneyler yapılırken katılımcılara çatlayıp kırılacak bir nesne kaldırdıklarını varsaymaları ve minimum kavrama kuvveti uygulayarak kaldırmaları gerektiği ama nesneyi düşürmemeleri gerektiği söylenmiştir. Çünkü kavrama görevinin türü belirlenerek, katılımcıların yüksek güvenlik marjı oranları ile güçlü kavrama eğilimi göstermeleri (Kossowsky ve ark., 2020) engellenmeye çalışılmıştır.

\subsection{Deney Düzeneğinin Kurulması}

Hassas kavrama ve kaldırma deneyleri için değiştirilebilir ağırlık ve yüzey özelliğine sahip Şekil 2'de görülen deney nesnesi tasarlanmıştır. Şekil 3'de ise deney nesnesinin ağırlığının ve yüzeylerinin değiştirilebilir özellikleri görülmektedir.

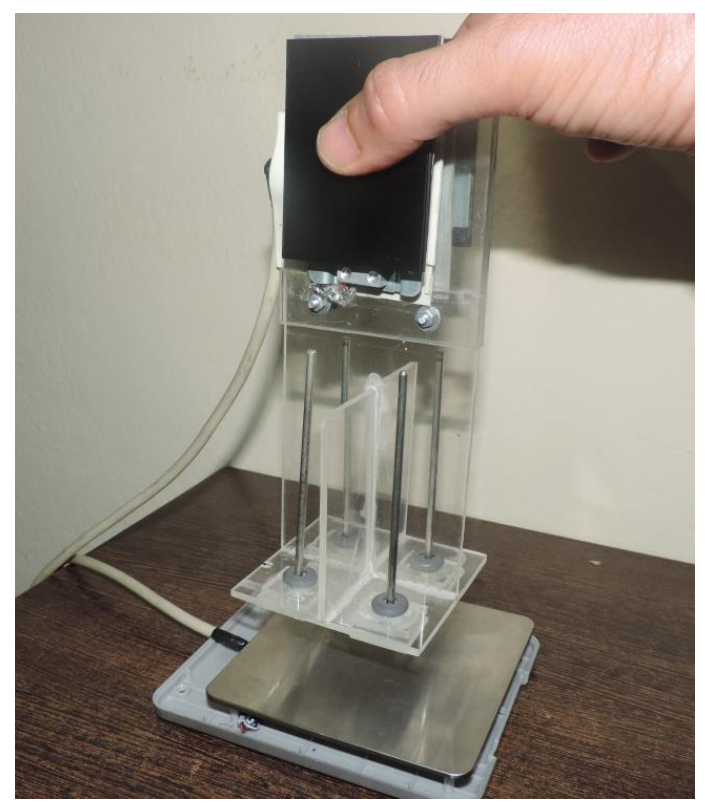

Şekil 2. Tasarlanan Deney Nesnesi

Şekil 3'de görüldüğü gibi deney nesnesinin çift taraflı yapışkan bant ile çıkarılıp takılabilen, akrilik plakalardan oluşan değiştirilebilir kavrama yüzeyleri mevcuttur. Kavrama kuvveti yük hücreleri tarafından algılanmaktadır. Kavrama yüzeyleri, yük hücrelerinin monte edildiği metal plakalara yapıştırılmaktadır. Deney nesnesinin ağırlığı, Şekil'3 de görüldüğü gibi değeri bilinen kütlelerin ağırlık çubuklarına takılması ile ayarlanmaktadır.
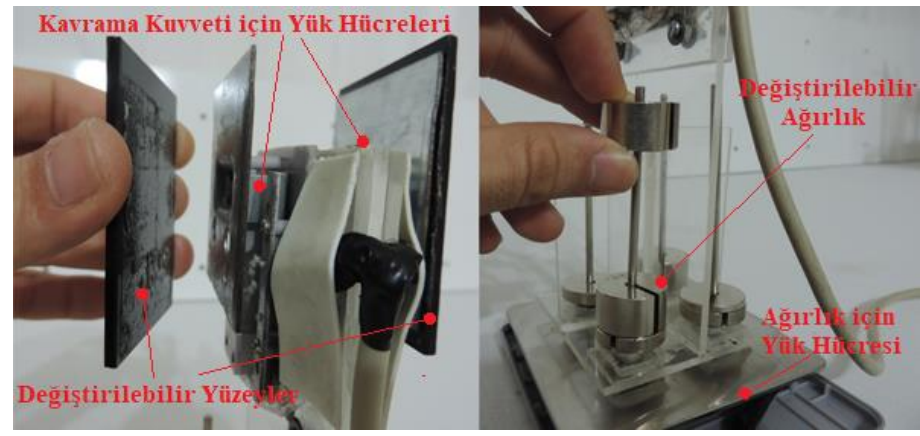

Şekil 3. Deney Nesnesinin Ă̆ırlı̆̆ının ve Yüzeylerinin Değiştirilebilir Özellikleri

\subsubsection{Değiştirilebilir Yüzeylerin Elde Edilmesi}

Deneylerin uygulanmasından önce Şekil 2'deki deney nesnesi için yüzey materyalleri belirleme çalışmaları yapılmıştır. Şekil 4'de görüldüğü gibi statik sürtünme katsayılarının ölçümü için HX711 sensör modül kartı, Arduino Uno R3 kart ve deney nesnesinden oluşan ölçüm düzeneği kurulmuştur. Kurulan düzenek ile statik sürtünme katsayılarının ölçümü için Şekil 5(a)'da görülen 2 eksenli 3 serbestlik derecesine sahip eyleyici sistem kullanılmıştır. Böylelikle deney nesnesinin değiştirilebilir yüzeylerine farklı sürtünme özelliklerine sahip materyaller yerleştirilerek Şekil 5(b)'de görüldüğü gibi statik sürtünme katsayıları ölçülmüştür.

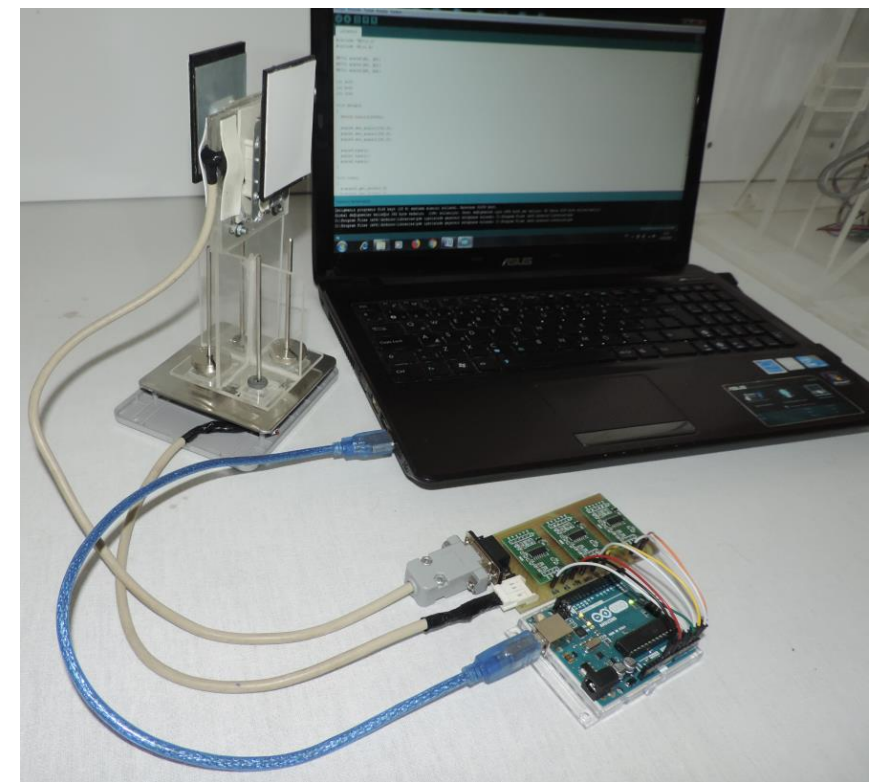

Şekil 4. Statik Sürtünme Katsayısı Ölçüm Düzeneği

Statik sürtünme katsayıları ölçülürken deney nesnesi sabit 900 g ağırlığa sahiptir. Başlangıç değeri 100 gf olacak şekilde 20 kere 20 gf 'luk artışlarla kavrama kuvveti uygulanmıştır. Arttırılan her kavrama kuvveti için kayma elde edene kadar dikey hareket sağlanmıştır. Böylece her yüzey materyali için yazılım tarafından Coulomb sürtünme yasasına göre Eşitlik 1 kullanılarak 20 adet statik sürtünme katsayısı hesaplanmıştır.

$$
\mu_{s}=\frac{F t_{\max }}{2 F_{n}}
$$

Eşitlik 1'de $\mu_{s}$, statik sürtünme katsayısını, $F t_{\text {max. }}$, kayma anında ölçülen maksimum teğetsel kuvveti (A ğırlık) ve $F n$ ise kayma anındaki normal kuvvet (Kavrama kuvveti) değerini ifade etmektedir. 


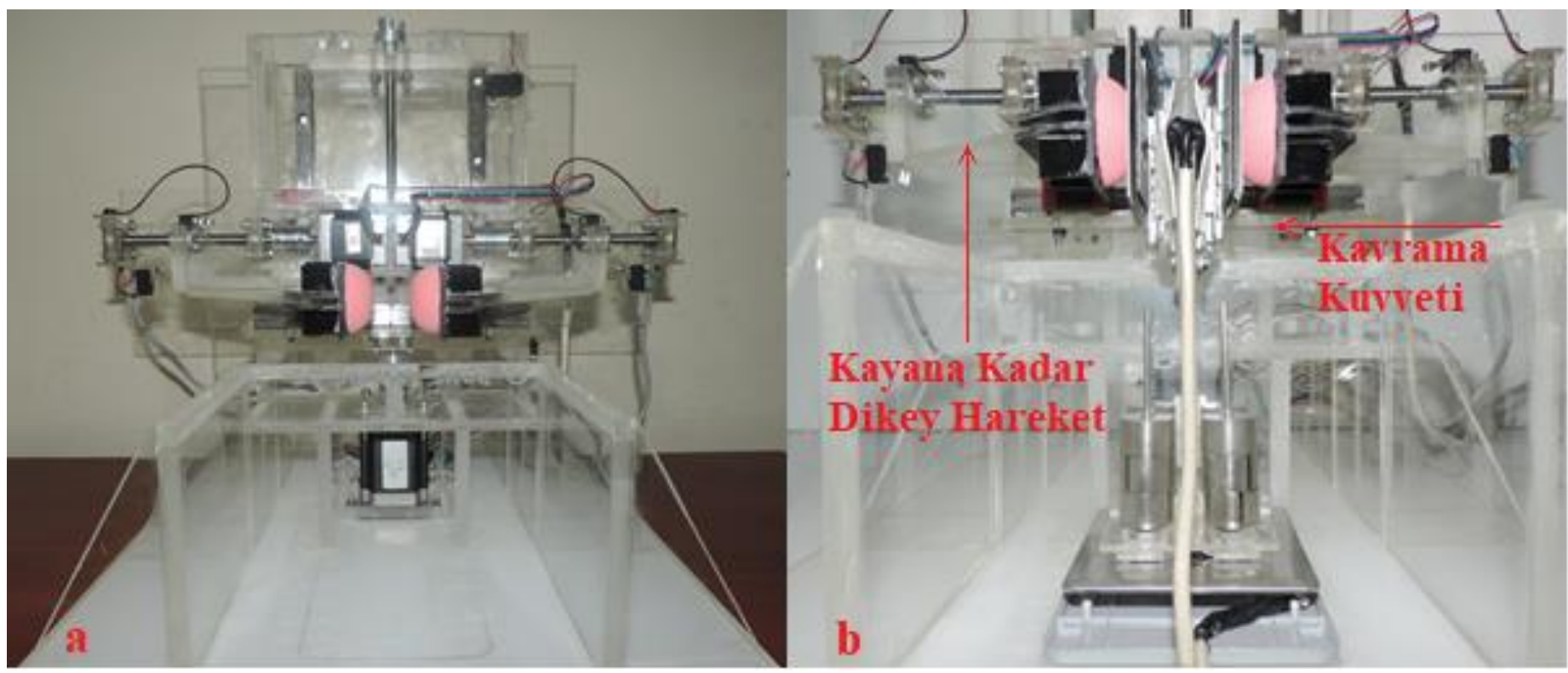

Şekil 5. Eyleyici Sistem (a) ve Statik Sürtünme Katsayısının Ölçümü (b)

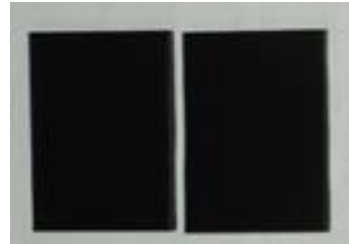

(a)

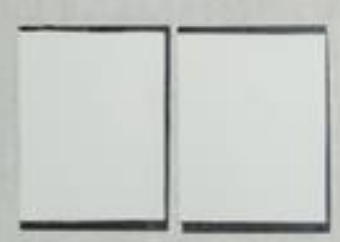

(b) (c)

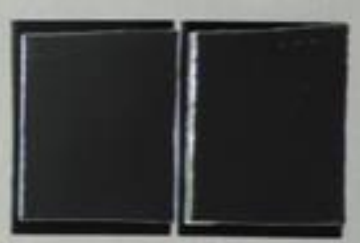

(e)

Şekil 6. Belirlenen Yüzey Materyalleri ile Oluşturulmuş Kavrama Yüzeyleri: PMMA (a) PP (b), A4 (c), HDPE (d), PTFE (e)

Yazılım içerisinde 20 adet $\mu_{s}$ değerinin aritmetik ortalaması hesaplanarak her ölçülen yüzey materyali için ortalama statik sürtünme katsayısı ( $\mu_{\text {sort. }}$ ) elde edilmiştir. Ölçüm yapılırken Şekil 7'da görüldüğü gibi eyleyicinin kavrama yüzeylerinde $36 \mu \mathrm{m}$ kalınlıkta BOPP (Biaxially Oriented Polypropylene-Çift Yönlü Gerdirilmiş Polipropilen) film kullanılmıştır. BOPP filmin kullanılmasının sebebi, insanlarla yapılacak olan deneyler ile eyleyici sistemle yapılacak olan ölçümlerde ortak ara yüz materyaline ihtiyaç duyulmasıdır. Çünkü insan parmak ucu derisi ile eyleyicinin kavrama yüzeyleri aynı materyallerde farklı sürtünme katsayıları ortaya çıkaracaktır.

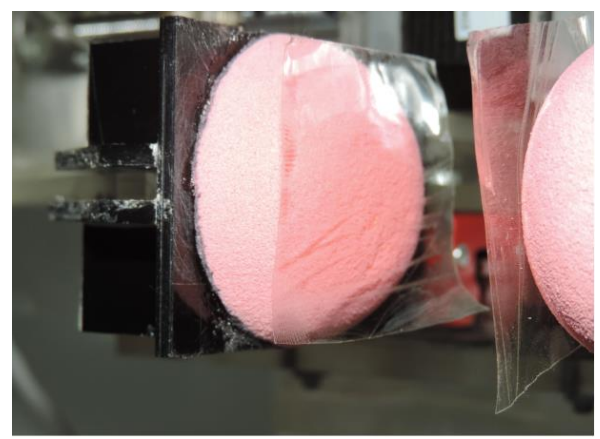

Şekil 7. Eyleyicinin Kavrama Yüzeylerinde BOPP Filmin Kullanımı

Yüzey materyalleri belirleme çalışmaları sonucunda 5 farklı yüzey materyali belirlenmiştir. Yüzey materyalleri kaygan ve sürtünmeli yüzeyleri temsil edebilecek şekilde belirlenmiştir.
Belirlenen materyaller akrilik plakaların üzerine yapıştırılarak Şekil 6'da görülen kavrama yüzeyleri elde edilmiştir. Kavrama yüzeyleri Şekil 3'de görülen deney nesnesine çift taraflı yapıştırıcı bant ile yapıştırılmaktadır. Tablo 1'de yüzey materyalleri ve BOPP film ile oluşturdukları ortalama statik sürtünme katsayıları $\left(\mu_{\text {sort. }}\right)$ verilmiştir.

Tablo 1. Yüzey Materyalleri ve BOPP Film ile Oluşturduklarl $\mu_{\text {sort. Değerleri }}$

\begin{tabular}{|l|l|}
\hline \multicolumn{1}{|c|}{ Yüzey Materyalleri } & $\boldsymbol{\mu}_{\text {sort }}$ \\
\hline PMMA (Polymethyl Methacrylate- Pleksiglas) & 0,75 \\
\hline PP (Polypropylene-Polipropilen) & 0,55 \\
\hline A4 Fotokopi Kâğıdı & 0,28 \\
\hline $\begin{array}{l}\text { HDPE (High Density Polyethylene- } \\
\text { Yüksek Yoğunluklu Polietilen) }\end{array}$ & 0,14 \\
\hline PTFE (Polytetrafluoroethylene-Teflon) & 0,07 \\
\hline
\end{tabular}

\subsection{Deneylerin Uygulanması}

Yüzey materyalleri ve statik sürtünme katsayıları elde edildikten sonra deneylerin uygulanmasına geçilmiştir. Yapılan deneylerde katılımcıların deney nesnesini kaldırdıkları andaki ölçüm verilerini okumak için Şekil 8'de görülen Matlab/Simulink modeli hazırlanmıştır. 


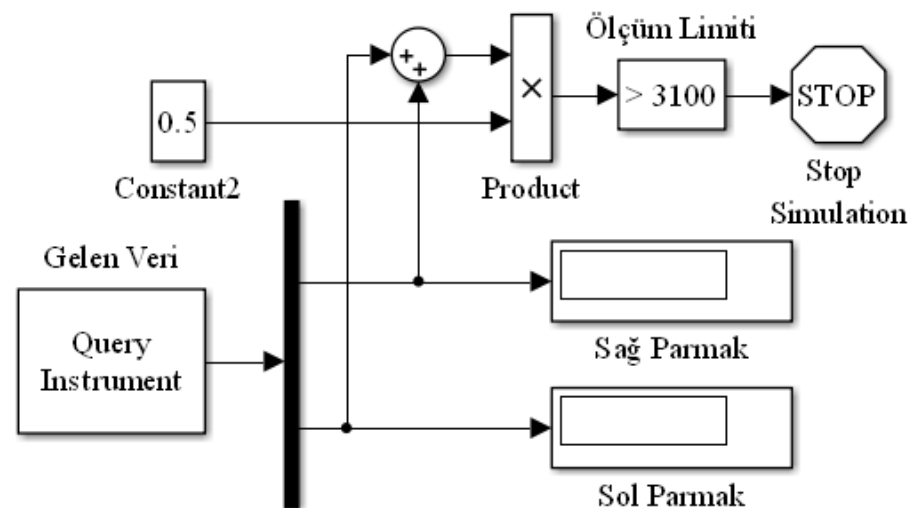

Şekil 8. Deneylerde Ölçüm Verilerini Okumak için Hazırlanan Matlab/Simulink Modeli

Deneyler esnasında eyleyicinin kavrama yüzeylerinde olduğu gibi katılımcıların parmak uçlarına da Şekil 9'de görüldüğü gibi BOPP film yapıştırılmıştır.

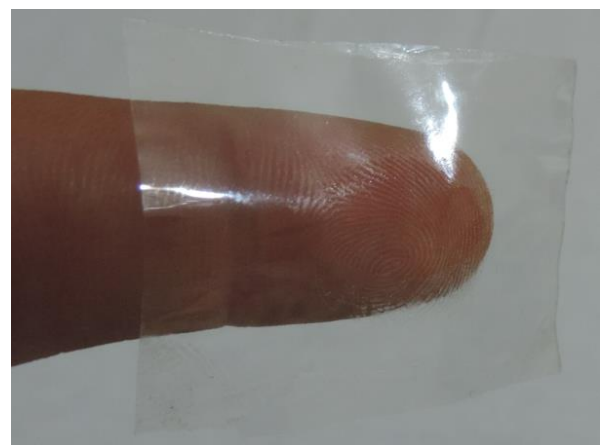

Şekil 9. İnsan Parmağının Ucunda BOPP Filmin Kullanımı

Şekil 10'da görüldüğü gibi her bir katılımcı ile 300 gf, 500 gf, 700 gf ve 900 gf olmak üzere 4 farklı ağırlık ve Şekil 7'de görülen 5 farklı kavrama yüzeyi için hassas kavrama ve kaldırma deneyi yapılmıştır. Her bir ağırlık ve yüzey için 5'er deneme yapılmıştır. Denemeler esnasında her iki parmağın uyguladıkları kuvvetlerin aritmetik ortalamaları alınmıştır. Katılımcıların her birinden, her bir yüzey ve ağırlık için 70 adet veri elde edilmiştir. Bazı yüzey ve ağırlıklar için yük hücrelerinin ölçüm limitleri aşıldığından veri elde edilememiştir. 14 katılımcıdan tüm deneyler sonunda 1035 adet veri elde edilmiştir.

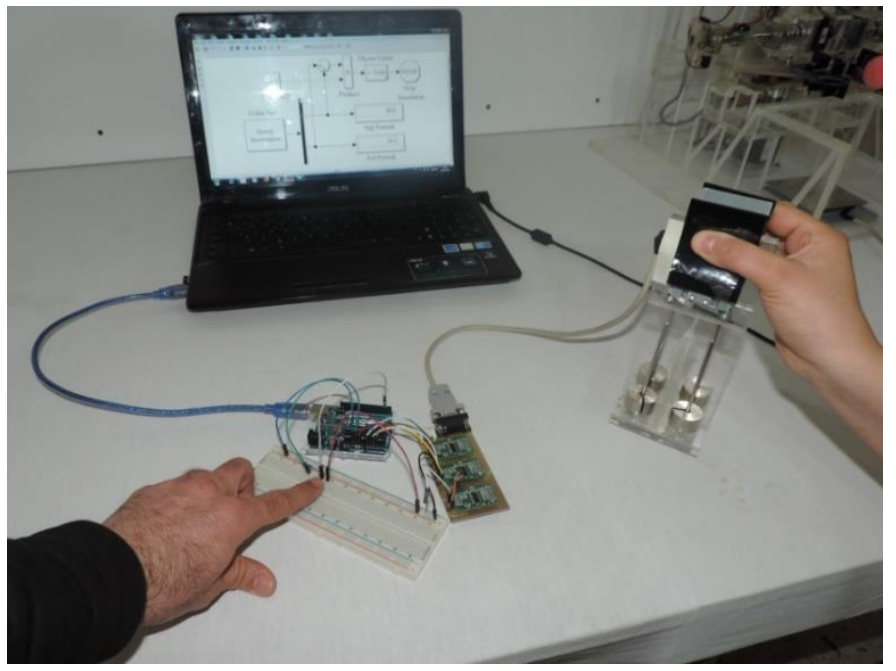

Şekil 10. Hassas Kavrama ve Kaldırma Deneylerinin Yapılışı
Deneylerden elde edilen kavrama kuvveti verileri kullanılarak 4 farklı ağırlık ve 5 farklı yüzey özelliği için Eşitlik 2 ile güvenlik marjı değerleri hesaplanmıştır. Hesaplanan 70 adet güvenlik marjı verilerinden en düşük değere sahip 14 veri belirlenmiştir. 14 verinin 70 veri içerisindeki tekrarlama sayılarına göre ağırlıklı ortalamaları hesaplanmıştır. Daha sonra Eşitlik 3 kullanılarak güvenlik marjı yüzde oranları hesaplanmıştır. Böylelikle insanların hassas kavrama görevinde değişen nesne koşullarına bağlı uyguladıkları optimum güvenlik marjı verileri ve buna bağlı güvenlik marjı yüzde oranları elde edilmiştir.

$$
\begin{gathered}
G m=F n_{g}-\frac{F t_{\max } .}{2 \mu_{S}} \\
\% G m=\left(\frac{G m}{F n_{g}-G m}\right) \cdot 100
\end{gathered}
$$

Eşitlik 2'de $G m$, güvenlik marjını ifade etmektedir. $F n_{g}$ ise katılımcıların deney nesnesini kaldırdıkları anda ölçülen güvenlik marjı içeren kavrama kuvvetidir. Eşitlik 3'de \%Gm, güvenlik marjı yüzde oranını ifade etmektedir.

\section{Araştırma Sonuçları ve Tartışma}

$\mathrm{Bu}$ çalışmada yapılan deneylerde insanların hassas kavrama görevinde nesnenin değişen ağırlığına ve değişen yüzey özelliğine göre uyguladıkları optimum güvenlik marjı verileri ve buna bağlı güvenlik marjı yüzde oranları elde edilmeye çalışılmıştır. Yapılan deneylerde 4 farklı nesne ağırlığ 1 ve 5 farklı yüzey sürtünme özelliği için kavrama kuvveti verileri elde edilmiştir. Elde edilen kavrama kuvveti verileri kullanılarak optimum güvenlik marjı verileri ve güvenlik marjı yüzde oranları hesaplanmıştır. Tablo 2'de insanlardan elde edilen optimum güvenlik marjı verileri görülmektedir. Tablo 3 'de ise Optimum güvenlik marjı verilerinden hesaplanan güvenlik marjı yüzde oranları görülmektedir.

Tablo 2. Elde Edilen Optimum Güvenlik Marjı Verileri

\begin{tabular}{|c|c|c|c|c|c|}
\hline \multirow{2}{*}{ Gm (gf) } & \multicolumn{4}{|c|}{ Ft $_{\text {max. }}$ (gf) } \\
\cline { 2 - 6 } & $\mathbf{3 0 0}$ & $\mathbf{5 0 0}$ & $\mathbf{7 0 0}$ & $\mathbf{9 0 0}$ \\
\hline \multirow{4}{*}{$\boldsymbol{\mu}_{\text {sort. }}$} & $\mathbf{0 , 7 5}$ & 33 & 51 & 81 & 120 \\
\cline { 2 - 6 } & $\mathbf{0 , 5 5}$ & 46 & 70 & 110 & 165 \\
\cline { 2 - 6 } & $\mathbf{0 , 2 8}$ & 71 & 105 & 160 & 247 \\
\cline { 2 - 6 } & $\mathbf{0 , 1 4}$ & 111 & 190 & LA & LA \\
\cline { 2 - 6 } & $\mathbf{0 , 0 7}$ & 174 & LA & LA & LA \\
\hline
\end{tabular}

Tablo 3. Elde Edilen Optimum Güvenlik Marjı Yüzde Oranları

\begin{tabular}{|c|c|c|c|c|c|}
\hline \multirow{2}{*}{$\% \mathbf{G m}$} & \multicolumn{5}{|c|}{ Ft $_{\text {max. }}$ (gf) } \\
\cline { 3 - 6 } & $\mathbf{3 0 0}$ & $\mathbf{5 0 0}$ & $\mathbf{7 0 0}$ & $\mathbf{9 0 0}$ \\
\hline \multirow{4}{*}{$\boldsymbol{\mu}_{\text {sort. }}$} & $\mathbf{0 , 7 5}$ & 16 & 15 & 17 & 20 \\
\cline { 2 - 6 } & $\mathbf{0 , 5 5}$ & 17 & 15 & 17 & 20 \\
\cline { 2 - 6 } & $\mathbf{0 , 2 8}$ & 13 & 12 & 13 & 15 \\
\cline { 2 - 6 } & $\mathbf{0 , 1 4}$ & 11 & 10 & LA & LA \\
\cline { 2 - 6 } & $\mathbf{0 , 0 7}$ & 9 & LA & LA & LA \\
\hline
\end{tabular}




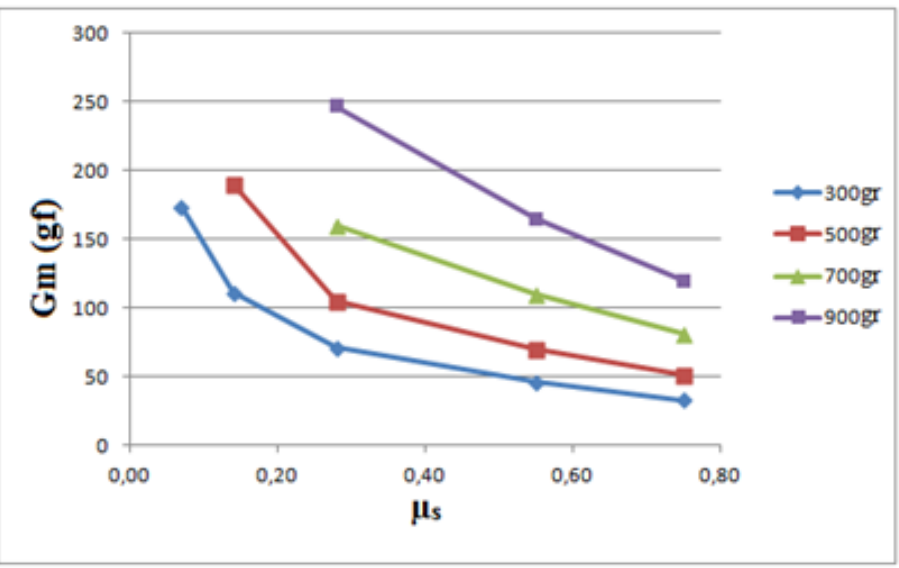

(a)

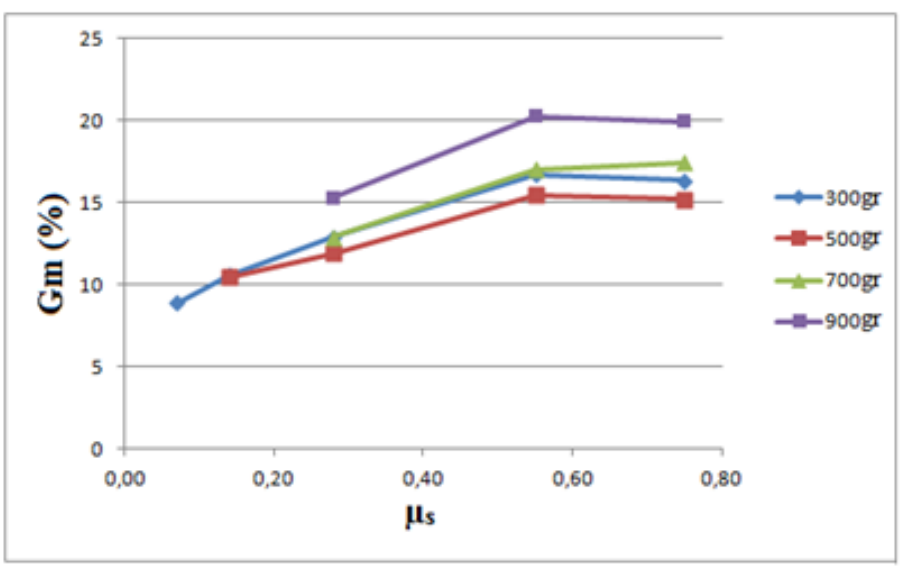

(c)

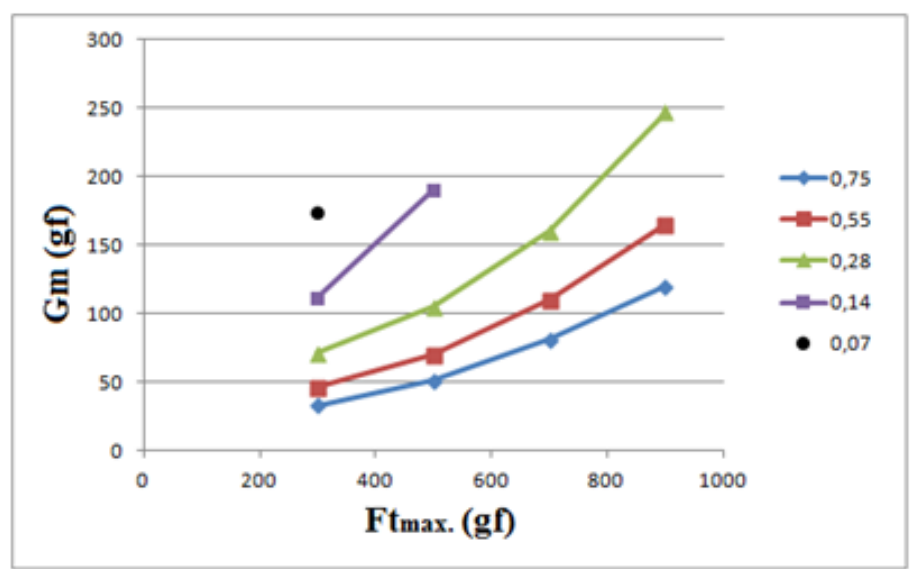

(b)

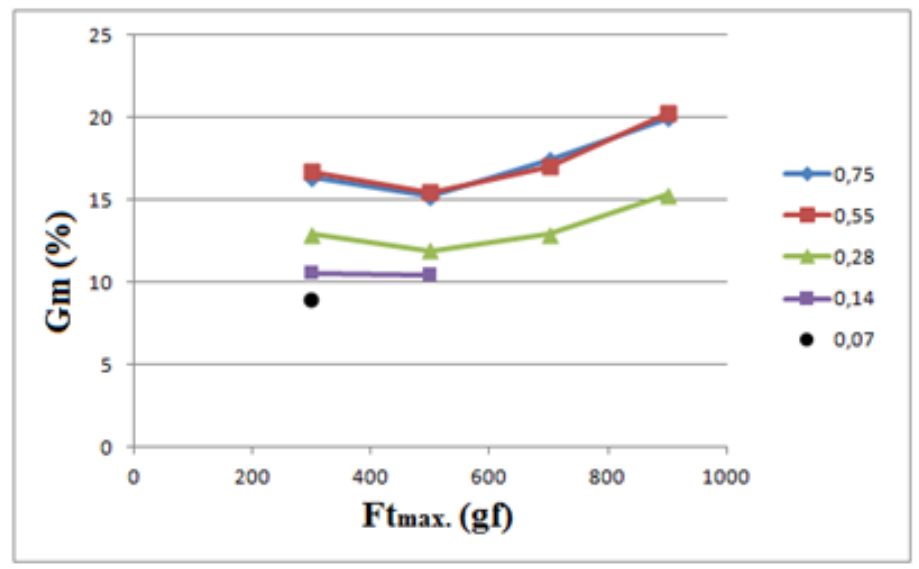

(d)

Şekil 11. Deneylerden Elde Edilen Optimum Güvenlik Marjı verilerine ve Güvenlik Marjı Yüzde Oranlarına ait Değişim Grafikleri: a) Statik sürtünme katsayısı değişimine göre güvenlik marjı değişimi, b) Ağırlık değişimine göre güvenlik marjı değişimi, c) Statik sürtünme katsayısına göre güvenlik marjı yüzde oranı değişimi, d) A ğırlık değişsimine göre güvenlik marjı yüzde oranı değişimi

Tablo 2 ve Tablo 3'deki LA (Limit Aşımı) ile gösterilen veri bölümleri, kullanılan yük hücrelerinin ölçüm limitlerinin aşıldığı yerlerdir. LA ile gösterilen bölümlerde ya yeterince ya da hiç veri elde edilememiştir. Şekil 11'de elde edilen optimum güvenlik marjı verilerine ve güvenlik marjı yüzde oranlarına ait grafikler görülmektedir.

Tablo 2 ve Tablo 3'deki veriler ile beraber Şekil 11'deki grafikler incelendiğinde güvenlik marjının statik sürtünme katsayısının ve ağırlığın değişimine duyarlı olduğu görülmektedir. Her ağırlık değeri için kayganlık arttıkça güvenlik marjı da artmıştır. Aynı şekilde her statik sürtünme katsayısı değeri için ağırlık arttıkça güvenlik marjı da artmıştır. Güvenlik marjı yüzde oranlarının ise sürtünmeli yüzeylerde ve düşük ağırlıklarda sabit eğilimli olduğu görülmektedir. Fakat ağırlık ve kayganlık arttıkça güvenlik marjı yüzde oranları da artmaktadır. Elde edilen sonuçlar literatürde önceki çalışmalarda sabit güvenlik marjı oranı yaklaşımının aksine yapılan son çalışmalardaki değişen nesne koşullarına göre değişken güvenlik marj1 görüşünü desteklemektedir. Literatürdeki çalışmalara katk1 olarak bu çalışmada değişen yüzey sürtünme özelliğine ve değişen ağırlığa bağlı olarak insanlarla yapılan deneylerden optimum güvenlik marjı verileri elde edilmiştir. Literatürdeki uygulanan sabit \%20 güvenlik marjı değeri, bu çalışmada elde edilen sonuçlara göre daha kaygan yüzeylere ve daha düşük ağırlığa sahip nesneler için yüksek bir oran ifade etmektedir.
Bu çalışmada değişen yüzey sürtünme özelliğine ve değişen ağırlığa göre güvenlik marjı oranının \%9 ile \%20 arasında değiştiği ortaya koyulmuştur.

\section{Sonuç}

Bu çalışmada insanın hassas kavrama yeteneğine ait gerçek veriler kullanılarak, güvenlik marjı odaklı kavrama kuvveti kontrolü için gerekli parametreler bulunmuştur. Yapılan deneylerden elde edilen optimum güvenlik marji verileri ile oluşturulan veri tabanı, bulanık mantık denetleyici ayarlanmasında kullanılacaktır. Böylelikle bir robot elin hassas kavrama görevinde özellikleri bilinmeyen bir nesnenin hassas bir şekilde kavranıp kaldırılması sağlanacaktır.

Çalışmada, insanlarla farklı yüzey özellikleri ve değişen ağırlıklarda hassas kavrama ve kaldırma deneyleri yapılmıştır. Yapılan deneylerde insanların hassas kavrama görevinde değişen nesne özelliklerine bağlı uyguladıkları optimum kavrama kuvveti değerleri elde edilmiştir. Optimum kavrama kuvveti değerlerinden optimum güvenlik marjı ve güvenlik marjı yüzde oranları elde edilmiştir. Bu çalışmada değişen yüzey sürtünme özelliğine ve değişen ağırlığa bağlı olarak güvenlik marjı oranının $\% 9$ ile $\% 20$ arasında değişen optimum verileri elde edilmiştir. 


\section{Teşekkür}

Bu çalışmayı 9861 proje numarası ile destekleyen Mustafa Kemal Üniversitesi Bilimsel Araştırma Projeleri Koordinatörlüğüne teşekkür ederiz.

\section{Kaynakça}

Cutkosky, M. R. (1989). On grasp choice, grasp models, and the design of hands for manufacturing tasks. IEEE Transactions on robotics and automation, 5(3), 269-279.

Mavrakis, N., Ghalamzan, E. A. M., \& Stolkin, R. (2017, September). Safe robotic grasping: Minimum impact-force grasp selection. In 2017 IEEE/RSJ International Conference on Intelligent Robots and Systems (IROS) (pp. 4034-4041). IEEE.

Okamura, A. M., Smaby, N., \& Cutkosky, M. R. (2000, April). An overview of dexterous manipulation. In Proceedings 2000 ICRA. Millennium Conference. IEEE International Conference on Robotics and Automation. Symposia Proceedings (Cat. No. OOCH37065) (Vol. 1, pp. 255-262). IEEE.

Bicchi, A., Salisbury, J. K., \& Brock, D. L. (1993). Contact sensing from force measurements. The International Journal of Robotics Research, 12(3), 249-262.

Su, Z., Hausman, K., Chebotar, Y., Molchanov, A., Loeb, G. E., Sukhatme, G. S., \& Schaal, S. (2015, November). Force estimation and slip detection/classification for grip control using a biomimetic tactile sensor. In 2015 IEEE-RAS 15th International Conference on Humanoid Robots (Humanoids) (pp. 297-303). IEEE.

Pettersson-Gull, P., \& Johansson, J. (2018). Intelligent robotic gripper with an adaptive grasp technique. Thesis for the Degree of Master of Science, Mälardalen University School of Innovation Design and Engineering, Västerås, Sweden.

Koda, Y., \& Maeno, T. (2006, October). Grasping force control in master-slave system with partial slip sensor. In 2006 IEEE/RSJ International Conference on Intelligent Robots and Systems (pp. 4641-4646). IEEE.

Wettels, N., Parnandi, A. R., Moon, J. H., Loeb, G. E., \& Sukhatme, G. S. (2009). Grip control using biomimetic tactile sensing systems. IEEE/ASME Transactions on Mechatronics, 14(6), 718-723.

Ho, V. A., \& Hirai, S. (2011). Understanding Slip Perception of Soft Fingertips by Modeling and Simulating Stick-Slip Phenomenon. In Robotics: Science and Systems.

Morita, N., Nogami, H., Higurashi, E., \& Sawada, R. (2018). Grasping force control for a robotic hand by slip detection using developed micro laser doppler velocimeter. Sensors, 18(2), 326.

Cutkosky, M. R., \& Howe, R. D. (1990). Human grasp choice and robotic grasp analysis. In Dextrous robot hands (pp. 531). Springer, New York, NY.

Westling, G., \& Johansson, R. S. (1984). Factors influencing the force control during precision grip. Experimental brain research, 53(2), 277-284.

Edin, B. B., Westling, G., \& Johansson, R. S. (1992). Independent control of human finger-tip forces at individual digits during precision lifting. The Journal of physiology, 450(1), 547-564.

Fu, Q., \& Santello, M. (2018). Improving fine control of grasping force during hand-object interactions for a soft synergy-inspired myoelectric prosthetic hand. Frontiers in neurorobotics, $11,71$.

Kossowsky, H., Farajian, M., Milstein, A., \& Nisky, I. (2020). The Effect of Between-Probe Variability in Haptic Feedback on Stiffness Perception and Grip Force Adjustment. bioRxiv.

Gaut, I. (2020). Evaluation of object attributes to study speedaccuracy trade-off of gloves using ISO 9241-411 standard. Thesis for the Degree of Master of Science, West Virginia University, Benjamin M. Statler College of Engineering and Mineral Resources, Morgantown, West Virginia.

Hadjiosif, A. M., \& Smith, M. A. (2015). Flexible control of safety margins for action based on environmental variability. Journal of Neuroscience, 35(24), 9106-9121.

Tremblay, M. R., \& Cutkosky, M. R. (1993, May). Estimating friction using incipient slip sensing during a manipulation task. In [1993] Proceedings IEEE International Conference on Robotics and Automation (pp. 429-434). IEEE.

Wettels, N., Parnandi, A. R., Moon, J. H., Loeb, G. E., \& Sukhatme, G. S. (2009). Grip control using biomimetic tactile sensing systems. IEEE/ASME Transactions On Mechatronics, 14(6), 718-723.

Bergmann Tiest, W. M., \& Kappers, A. M. (2019). The influence of visual and haptic material information on early grasping force. Royal Society open science, 6(3), 181563.

Johansson, R. S., \& Flanagan, J. R. (2008). 6.05-Tactile sensory control of object manipulation in humans. Senses Compr. Ref. Acad. Press NY NY, 67-86.

Wiertlewski, M., Endo, S., Wing, A. M., \& Hayward, V. (2013, April). Slip-induced vibration influences the grip reflex: A pilot study. In 2013 World Haptics Conference (WHC) (pp. 627-632). IEEE.

Gibo, T. L., Bastian, A. J., \& Okamura, A. M. (2013). Grip force control during virtual object interaction: effect of force feedback, accuracy demands, and training. IEEE transactions on haptics, 7(1), 37-47.

Farajian, M., Leib, R., Kossowsky, H., Zaidenberg, T., MussaIvaldi, F. A., \& Nisky, I. (2020). Stretching the skin immediately enhances perceived stiffness and gradually enhances the predictive control of grip force. Elife, 9, e52653.

Grover, F. M. (2018). Intermittency between grip force and load force. (Doctoral dissertation, University of Cincinnati).

Wang, X., Xiao, Y., Zhao, Y., \& Fan, X. (2017). Grasping force optimization algorithm of soft multi-fingered hand based on safety margin detection. jiqiren/Robot, 39, 844-852.

Zadeh, L. A. (1965). Fuzzy sets. Information and control, 8(3), 338-353.

Kocabaş, A. (2017). Design and optimization of a fuzzy logic based maximum power point tracker for pv panel (Doctoral dissertation, Karadeniz Teknik Üniversitesi).

Tüysüz, M. (2018). Hibrit güç sistemlerinde maksimum güc noktası takibi için bulanı denetleyicinin optimizasyonu (Doctoral dissertation, Karadeniz Teknik Üniversitesi).

Rodriguez, R. M., Martinez, L., \& Herrera, F. (2011). Hesitant fuzzy linguistic term sets for decision making. IEEE Transactions on fuzzy systems, 20(1), 109-119. 